\title{
Teoría de la comunicación y paisaje. Las geografías del sujeto y la perspectiva interpretativa de la comunicación
}

\section{Communication and Landscape Theory. The Geographies of the Subject and the Interpretation Perspective of Communication}

\author{
Joan Nogué. Universidad de Girona
}

Jordi de San Eugenio Vela. Universidad de Vic

\author{
Recibido: 6-V-2009 - Aceptado: 9-X-2009 \\ Resumen:
}

El estudio de las implicaciones comunicativas presentes en el paisaje tangible e intangible circundante abre un amplio abanico de posibilidades para el tratamiento de la denominada comunicación en el paisaje. El análisis de los efectos que el entorno genera en los procesos de comunicación humana, el seguimiento de los procesos comunicativos mediante los cuales se mercadea con el paisaje, la construcción de imaginarios individuales y colectivos a partir de la interacción ciudadanía-territorio, el tránsito de espacio a lugary, más recientemente, la habilitación de identidades territoriales a partir de la construcción de una imagen de marca de ciudad o de país -léase promoción turística, citymarketing y/o branding, entre otros-presentan, en todos los casos, amplias connotaciones de alcance comunicativo. La búsqueda del mensaje presente en el paisaje plantea, en este mismo sentido, el tratamiento del espacio a modo de sistema de comunicación. En cualquier caso, parece claro que, en los últimos tiempos, asistimos a una cierta eclosión de procesos de comunicación concebidos desde la realidad existente en el espacio y más aún, en el paisaje, por lo que se hace necesario avanzar hacia un tratado comunicativo del paisaje.

Palabras clave:

Paisaje, comunicación, identidad, territorio.

\section{Abstract:}

The study of the communicative implications in the tangible and intangible surrounding landscape opens a wide range of possibilities for the study of the so-called landscape communication. The analysis of the effects that the environment generates in the human communication processes, the following-up of the communication processes related to the landscape marketing, the construction of individual and collective imaginaries through the citizenship-territory interaction, the conversion of space to place and, more recently, the emergence of territorial identities through the construction of a brand image of a city or a country -that is, tourist promotion, city marketing and/or branding, among others - present many connotations of communicative scope. The search of the message in landscape implies the treatment of space as a communication system. It seems to be clear that nowdays we assist to an emergence of communication processes conceived from the existing reality in the space and even more in the landscape. For all these reasons it is necessary to walk towards a communicative landscape theory.

Key Words:

Landscape, Communication, Identity, Territory. 


\section{Introducción, justificación y método}

El artículo que se presenta a continuación pretende fijar algunos cimientos teóricos a partir de los cuales vincular el pensamiento geográfico con el comunicativo y, en este contexto, considerar al paisaje como elemento activo de comunicación y las posibilidades de estudio que de ello se derivan. La habilitación de un lenguaje del territorio o, en cualquier caso, el establecimiento de metodologías de análisis que permitan plantearse el estudio del espacio geográfico y de sus usos comunicativos, enriquece de manera extraordinaria los estudios en comunicación. Así pues, la presente investigación, de carácter teórico, tratará de mostrar las posibilidades de análisis del paisaje desde el punto de vista de la comunicación, con el fin de crear las sinergias suficientes que nos permitan ampliar el ámbito de estudio de ambas variables. En efecto, esta contribución pretende aportar nuevas evidencias para la mejora de la inteligibilidad simbólica del paisaje, además de favorecer la unión de aquellos fundamentos teóricos interdisciplinarios que permitan la consideración de una nueva visión comunicativa del paisaje.

En este contexto, tanto el objetivo principal de la investigación (la revisión y posterior fusión de las teorías geográfica y comunicativa con el fin de habilitar un corpus teórico relevante a partir del cual iniciar posteriores investigaciones relacionadas con el binomio comunicación-paisaje), como el fenómeno que se pretende analizar (el paisaje a modo de elemento activo de comunicación) conducen inevitablemente a una investigación de tipo teórico y de carácter sistémico. Esta concepción sistémica se construye a través de un razonamiento abstracto, soportado en deducciones, analogías, y oposiciones, aunque se inspire, necesariamente, en el comportamiento de objetos reales y en los conocimientos previos sobre tales objetos (Quivy y Campenhoudt, 1997). En relación con el método de investigación utilizado, cabe señalar que la construcción de un modelo teórico que posibilite el estudio del paisaje desde una perspectiva eminentemente comunicativa requiere la puesta en relación de diferentes disciplinas auxiliares (geografía y comunicación en el caso concreto que ocupa el presente texto) que permitan visualizar una lógica de relaciones entre un mismo sistema de análisis.

La incipiente necesidad de analizar los vínculos que se establecen entre la comunicación y el paisaje o, dicho de otro modo, el camino hacia un posible tratado comunicativo del paisaje justifica, de antemano, el despliegue de una amplia reflexión teórica que permita afrontar su estudio simbólico a modo de elemento activo de comunicación. Por todo ello, parece de recibo plantearse una investigación con un marcado cariz teórico y argumentativo bajo la concepción de un paradigma interpretativo, epistemológicamente orientado a comprender e interpretar la capacidad de evocación comunicativa inherente al paisaje. A nivel ontológico, mantiene una postura que apela necesariamente al relativismo y, por tanto, su metodología se encuadra en 
un ámbito esencialmente ideográfico y cualitativo. En efecto, el desarrollo de la investigación -en esta primera fase aún de carácter teórico y muy soportada en el vaciado bibliográfico y las aportaciones inéditas de los autores del presente texto-, ha requerido del establecimiento de un proceso de desdoblamiento teórico basado en las aportaciones de las geografías del sujeto y la perspectiva interpretativa de la teoría de la comunicación.

Los estudios más prolíficos relacionados con la comunicación y el paisaje provienen de la comunicación humana en su nivel de estudio macrosocial (de masas). En este sentido, los procesos de promoción turística de los territorios, implementados, en muy buena medida, a partir de la comercialización de una imagen del destino -normalmente turística- capitalizada por la exposición al "gran público" de un paisaje de referencia que se convierte en icono -imagen universal-, son el ejemplo más claro de uso comunicativo del paisaje con finalidades mercantilistas. En efecto, existen numerosos estudios que se ocupan, entre otros, de los procesos de construcción de la imagen turística tangible e intangible, donde el paisaje, una y otra vez, desempeña un papel muy destacado. En conjunto, representan, tan sólo, algunos de los ejemplos más recientes del creciente interés dispensado a los procesos de comunicación vehiculados desde el territorio. En efecto, los procesos de creación de identidades territoriales o bien el intento de fijación de esas mismas identidades en el imaginario colectivo a modo de carta de presentación de los territorios, constituyen en la actualidad algunas de las manifestaciones más elocuentes referidas a la puesta en relación de las variables paisaje, identidad y comunicación.

La teoría de la comunicación ha explorado con cierta profundidad los conceptos de espacio y de medio ambiente, pero no así el de paisaje, un concepto fundamental en la tradición académica geográfica de los dos últimos siglos y, hoy, además, un elemento clave en las nuevas políticas de ordenación del territorio. En efecto, el Convenio Europeo del Paisaje, impulsado por el Consejo de Europa y aprobado en Florencia a finales del año 2000, ha contribuido en gran manera a introducir el paisaje en las políticas territoriales de todos los estados que ya lo han ratificado, entre ellos España, país en el que el Convenio entró en vigor el 1 de marzo de 2008. Esta ratificación va a comportar -está comportando ya- un salto cualitativo extraordinario en lo que se refiere al tratamiento del paisaje no sólo en la legislación de carácter territorial y urbanístico, sino también en el debate social y cultural a través, en buena medida, de los medios de comunicación o, mejor dicho, de la comunicación en sentido amplio.

No hay duda de que, en el contexto de la contemporaneidad, el paisaje es uno de los conceptos geográficos con una dimensión comunicativa más notable y, sin embargo, precisamente en unos momentos en los que se reconoce de manera explícita y unánime el enfoque inter y multidisciplinario en el estudio del paisaje, 
se echa en falta, desde nuestro punto de vista, la incorporación de la teoría de la comunicación a dicho estudio. El paisaje es utilizado una y otra vez en el proceso comunicativo contemporáneo en prácticamente todas sus formas y variantes y, sin embargo, no existe una lectura paisajística de este proceso, un análisis de sus componentes esenciales, una aproximación a sus complejas y poliédricas dimensiones. A cubrir este vacío quiere contribuir este artículo, planteado a modo de ensayo metodológico desde, simultáneamente, las teorías geográfica y comunicativa. La geografía es una de las disciplinas científicas que más ha aportado al estudio del paisaje, por lo que a ella vamos a recurrir a la hora de identificar aquellos elementos que puedan sernos de utilidad para empezar a edificar un tratado comunicativo del paisaje.

El trabajo que se presenta a continuación se inicia con una breve presentación del concepto fundamental que articula esta contribución, el paisaje, resaltando de él su intrínseca relación con los procesos de identificación territorial. Con ello se quiere mostrar que la dimensión intersubjetiva, tan propia del concepto de comunicación, es inherente también al concepto de paisaje. A continuación se muestran las correspondencias y afinidades compartidas por la geografía y la teoría de la comunicación a partir de una comparación de la evolución teórica y metodológica de ambas disciplinas a lo largo de la segunda mitad del siglo pasado en lo referente al estudio del sujeto y del mundo subjetivo. Posteriormente, el artículo analiza algunos de los usos comunicativos del paisaje más notorios para llegar a unas conclusiones finales en las que se apuesta por un programa de investigación que vincule definitivamente el paisaje y la teoría de la comunicación.

\section{Comunicación, identidad y espacio}

La intervención de la variable espacio en el estudio de la comunicación tiene un notable recorrido. Destacados autores del ámbito de la comunicación y de la geografía así lo han atestiguado. Es el caso, por ejemplo, del francés Abraham A. Moles, destacado pensador, filósofo y teórico de la comunicación, quien señala (1972: 737): "La ecología de la comunicación será la ciencia, en desarrollo, de las relaciones e interacciones existentes entre las diferentes actividades de comunicación en el interior de un conjunto social disperso en el territorio: empresa, ciudad, estado, globo terrestre, etc". En relación con la dualidad espacio-comunicación manifestada por Moles también se pronuncia Miquel de Moragas (1981: 155): “[...] La ecología de la comunicación, según el planteamiento físico-teórico de Moles, pretenderá incluir toda la estructura comunicativa que afecta al hombre en el cosmos. La ecología de la comunicación interpretará científicamente la interacción entre especies comunicativas diferentes, próximas o lejanas, táctiles, visuales o auditivas, fugaces o registradas, masivas o no masivas, que actúan sobre el individuo en el espacio de su tiempo 
cotidiano [...]. El mundo biológico, el mundo físico, el mundo económico, están ligados a la idea de interconexión y, en definitiva, de comunicación".

Alicia Lindón, en la obra La vida cotidiana y su espacio-temporalidad se expresa del siguiente modo (2000: 11-12): "El espacio de la experiencia práctica, el espacio en el cual se produce la dualidad interacción/intersubjetividad, constituye un territorio en el cual se inscribe un lenguaje natural y en el cual se produce la elaboración de un dominio de este lenguaje [...]. El espacio visto como un lenguaje no verbal puede ser reconocido a través de dos grandes modalidades de emergencia del sentido. Una está constituida por las percepciones significativas que hablan del espacio tal como es percibido (por ejemplo, el sentido de lugar) y la otra, por las prácticas significantes que dan cuenta del sujeto tal como se comporta y actúa en el espacio, y lo que significa para él y para los otros (por ejemplo, la "territorialidad y la apropiación del territorio") [...] El espacio no se limita al locus externo a la experiencia, sino que carga con los sentidos y significados de las experiencias [...]”. Y, por su parte, en el el ámbito de la psicología, Pablo Fernández Christlieb (2000: 163 y 167) afirma lo siguiente: "Cada territorio donde se instaura la atmósfera de una comunidad, comporta, como hecho inherente mismo, un tipo determinado de comunicación, con un resultado -otro hecho inherente- determinado de conocimiento. [...] Cuando se habla de tierra o territorio también, porque las características físicas que se pueden atribuir en el espacio constituyen rasgos simbólicos y psicológicos del objeto que se está estudiando. [...] El suelo es una instancia tan simbólica como lo es el pensamiento y el sentimiento, y entonces se habla de paisajes "alegres" o mares "embravecidos".

La interacción espacio-ciudadanía abre nuevos campos de análisis para la comunicación. Tanto es así que, en opinión de Rossana Reguillo (1997), se puede concebir el estudio del binomio comunicación-espacio a partir de tres puntos de vista fundamentales: la interacción comunicativa (redes y relaciones); el análisis a propósito de la lucha que se establece con motivo de apropiaciones y definiciones legítimas de objetos y prácticas sociales (poder y hegemonía); y fuentes a partir de las cuales alimentar las representaciones y el imaginario colectivo que orienta la acción (medios y mediaciones).

La importancia comunicativa del espacio y del tiempo, el estudio de la pertenencia territorial o, inclusive, el análisis del consumo cultural del espacio, son algunos de los argumentos temáticos a partir de los cuales se pueden establecer lazos de colaboración entre la comunicación y el espacio. El escenario del medio físico (tangible) se conforma, de este modo, como el espacio donde la ciudadanía realiza determinadas prácticas sociales. En la actualidad, de lo que se dispone es de un conjunto de acercamientos teóricos, ya que no existe una teoría fundamentada que permita abordar, de forma unidireccional, el estudio de los mensajes y de los procesos de comunicación implícitos en el espacio. 
En cualquier caso, situar el espacio en el punto de mira de la comunicación tiene que servir, entre otras muchas cosas, para construir un modelo inteligible de interpretación del espacio físico que nos envuelve, poniendo el énfasis en su alto poder de significación. En efecto, se trata de "desnudar" al territorio entendido como escenario de comunicación, o si se quiere, como escenario de mediación. Cabe entender al espacio geográfico como una forma de expresión, de significación y, en consonancia con esta disyuntiva, la comunicación puede proporcionar una valiosa aportación a la descodificación de los valores intangibles implícitos en el espacio. Por otro lado, en el contexto de determinadas localizaciones, se desarrollan un conjunto de procesos de comunicación (a nivel intra e interpersonal), condicionados por el propio territorio, el cual mediatiza, sin duda, la acción comunicativa. Así pues, la interacción humana con el espacio que le es propio (territorios de la cotidianeidad) y con el espacio que le es ajeno (territorios de lo desconocido) posee, en ambos casos, connotaciones comunicativas que también se deberán tener en cuenta.

Es por todo ello que el estudio del territorio desde el prisma de la comunicación delimita ocho líneas de trabajo fundamentales (San Eugenio, 2008): territorio, cognición y apropiación del espacio; intervenciones del entorno en los procesos de comunicación humana; estrategias de promoción y comercialización del territorio; comunicación medioambiental; la organización de eventos como iniciativa de consumo espacial; nuevas tendencias en comunicación territorial: Citymarketing, Place branding, etc.; medios de comunicación de masas y tratamiento del espacio; y, finalmente, territorio y comunicación digital.

El lenguaje del lugar, en el cual se incluye la transmisión de mensajes, plantea muchas posibilidades de tratamiento desde el punto de vista de la comunicación. Pueden incluirse, entre otros, estudios de recepción, análisis del discurso, etnografías, etc., todo ello en busca de un objetivo que a estas alturas parece claro: interpretar el espacio e inclusive, dotarlo de un tratamiento a modo de sistema de comunicación: el entorno como mediación, como sistema de comunicación físico y social (Mela, 1994).

\section{Paisaje e identidad territorial}

Nunca como ahora se había hablado tanto de paisaje, ya sea en los ámbitos especializados o en los grandes medios de comunicación. Hay varias razones que explican este fenómeno: la progresiva concienciación ambiental de los últimos veinte años, que ha beneficiado indirectamente al paisaje; la extensión galopante de la ciudad dispersa vinculada al auge extraordinario del sector de la construcción, que, por primera vez en la historia, ha sido capaz de transformar la fisonomía de miles de hectáreas en un cortísimo espacio de tiempo; la implantación sobre el territorio de infraestructuras de todo tipo, algunas de ellas antipáticas y molestas a los ojos de los ciudadanos que ya vivían en esos enclaves; una mayor sensibilidad estética por parte 
de determinados grupos y colectivos capaces de crear opinión en los medios de comunicación y, finalmente, el papel relevante que el paisaje tiene y ha tenido siempre en la formación y consolidación de identidades territoriales. En general, la gente se siente parte de un paisaje, con el que establece múltiples y profundas complicidades. Este sentimiento es legítimo, ancestral y universal y, si bien es verdad que la tensión dialéctica entre lo local y lo global generada por lo que habitualmente entendemos por globalización está afectando muchísimo a los lugares, también lo es que, en buena medida, seguimos actuando como una cultura territorializada y, en ella, el paisaje ejerce un rol social y cultural destacado. El paisaje ha sido y es un ingrediente fundamental del sentido de lugar de la gente, a pesar de que los lugares -y sus paisajeshan acusado el impacto de las telecomunicaciones, de la mayor velocidad de los sistemas de transporte, de la mundialización de los mercados, de la estandarización de las modas, de los productos y de los hábitos de consumo. A pesar de todo ello, la inmensa mayoría de los lugares siguen conservando su carácter y, en ellos, la gente no ha perdido aún -o no del todo- su sentido de lugar. Se resiste a perderlo, no se resigna a que le eliminen de un plumazo la idiosincrasia de sus paisajes y, en el fondo, la conflictividad territorial hoy existente es una prueba de ello.

El paisaje sigue desempeñando un papel fundamental no sólo en el proceso de creación de identidades territoriales, a todas las escalas, sino también en su mantenimiento y consolidación. Y esto es así porque al hablar de paisaje estamos hablando de una porción de la superficie terrestre que ha sido modelada, percibida e interiorizada a lo largo de décadas o de siglos por las sociedades que viven en ese entorno. El paisaje está lleno de lugares que encarnan la experiencia y las aspiraciones de la gente; lugares que se convierten en centros de significado, en símbolos que expresan pensamientos, ideas y emociones varias. El paisaje no sólo nos presenta el mundo tal como es, sino que es también, de alguna manera, una construcción de este mundo, una forma de verlo. El paisaje es, en buena medida, una construcción social y cultural, siempre anclado -eso sí- en un substrato material, físico. El paisaje es, a la vez, una realidad física y la representación que culturalmente nos hacemos de ella; la fisonomía externa y visible de una determinada porción de la superficie terrestre y la percepción individual y social que genera; un tangible geográfico y su interpretación intangible. Es, a la vez, el significante y el significado, el continente y el contenido, la realidad y la ficción. La gran mayoría de las definiciones y acepciones del término paisaje incluye este elemento perceptivo, esta dimensión cultural ya aludida, incluido el Convenio Europeo del Paisaje, ya citado más arriba, que define al mismo como "un área, tal y como la percibe la población, cuyo carácter es el resultado de la interacción de factores naturales y/o humanos". Así pues, se mire por donde se mire, en la propia esencia del concepto de paisaje existe una dimensión comunicativa, puesto que este no se concibe sin un observador, ya sea individual o colectivo, que, con su mirada al mismo, dota de identidad a un territorio determinado. 


\section{El estudio del sujeto y del mundo subjetivo en las teorías geográfica y de la comunicación. El auge de las sociologías interpretativas}

La geografía de la percepción y del comportamiento ambiental aparece en la década de los 60 del siglo XX y fija sus preceptos teóricos fundamentales en el conductismo (behaviorismo). Esencialmente representa la antesala de las que se conocerán como "geografías del sujeto" e implica la incorporación de la dimensión interior del ser humano. Se fundamenta en la percepción psicológica del medio a través de los sentidos y en el comportamiento de la sociedad mediante el estudio de su conducta (Santarelli y Campos, 2002). Se parte de la base de que la percepción humana desarrolla un papel decisivo en el proceso de formación de imágenes del medio real, lo que acabará repercutiendo sobre las bases del comportamiento individual y grupal. Así pues, la mente humana, donde tiene lugar el proceso de percepción, la formación de la imagen y la posterior toma de decisiones, representa per se un nuevo campo de investigación geográfica. Max Sorre ya avanzó en su obra Rencontres de la géographie et de la sociologie (1957) que el territorio y todos sus componentes son interpretados de forma diferente según los individuos y las épocas. Por su parte, otro clásico como Kevin Lynch, en su obra The image of the city (1960), nos advirtió de la enorme relevancia de la percepción en el proceso de aprehensión urbana. Otros autores, como Antoine Bailly, con su trabajo La Perception de l'espace urbain: les concepts, les méthodes d'étude, leurs utilsation dans la recherche géographique (1977), o Yi-Fu Tuan con Images and Mental Maps (1975) y, finalmente, Armand Frémont con La región, espace vécu (1976), consolidan, entre otros, los postulados fundamentales de la percepción en geografía.

Los estudios sobre percepción del medio se iniciaron en Chicago (Estados Unidos) en los años sesenta. El primer geógrafo que abordó la temática perceptiva del espacio fue David Lowenthal, quien, a través de su obra Geography, Experience and Imagination: Towards a Geographical Epistemology (1961), abrió el camino para la posterior exploración de las geografías personales. Roger M. Downs, en su obra Geographic Space Perception. Past Approaches and Future Prospects (1970), enfoca la percepción del medio desde tres puntos de vista: estructural (identidad y estructura de las percepciones del espacio geográfico), evaluativo (valoración por parte de los individuos de diferentes aspectos del medio con vistas a la adopción de un determinado comportamiento) y preferencial (preferencia de los individuos hacia determinados aspectos o elementos geográficos y su influencia en su comportamiento). En este apartado cabe destacar, a modo de ejemplo, los mapas mentales (mental maps) de Peter Gould (1966-1967).

A partir de 1970 aparece una nueva perspectiva, que se postula a sí misma como alternativa crítica contra el positivismo lógico, y que destaca al sujeto como centro de la construcción geográfica, yendo más allá de la pura percepción. Es la denominada geografía humanística, una geografía del mundo vivido centrada en 
los valores y en el concepto de lugar como centro de significado, de identificación personal y foco de vinculación emocional. Esta corriente se apoya en las nociones propuestas por la fenomenología, el existencialismo, el humanismo y el idealismo. La fenomenología de Husserl, las concepciones filosóficas que resaltan el papel de la comprensión en el proceso de conocimiento, y con ello del individuo; los postulados de Heidegger, e incluso la crítica de raíz marxista de los representantes de la Escuela de Frankfurt, como Marcuse y Habermas, constituyen el soporte de la crítica humanística a la geografía analítica y sus presupuestos. Se persigue un conocimiento holístico, subjetivo, vivido, empático del espacio a través de una inmersión en el mismo, identificándose como parte del mismo. Sus representantes más destacados fueron Yi Fu Tuan, Anne Buttimer y Edward Relph, entre muchos otros. El concepto clave en geografía humanística es el de lugar, concepto cargado de significados y valores inseparables de la experiencia humana. Se observa, también, un renovado interés por el paisaje y por una metodología que resalta la memoria histórica, la observación participativa, el trabajo de campo, o el uso de la literatura y del arte como forma de aproximación al lugar. Se incide como nunca antes en las dimensiones simbólicas del espacio, la indagación sobre las particularidades de los lugares y la relación entre espacio y sujeto.

Para terminar este telegráfico repaso a las grandes corrientes del pensamiento geográfico contemporáneo habría que hacer mención a la geografía posmoderna, surgida en el contexto de la posmodernidad. El posmodernismo va asociado a la crisis del proyecto ilustrado de la modernidad en la filosofía, la cultura y la ideología, y muestra un gran interés por nuevos lenguajes y formas de representación, por el fin de las verdades absolutas, así como por la deconstrucción de viejas teorías y métodos (Albet, 1994). El posmodernismo en geografía se ha traducido en una renovada atención a las problemáticas que caracterizan al lenguaje y a las formas de expresión y representación del mundo y de la experiencia temporal y espacial vivida (Nogué, 2008b). Ha contribuido a la introducción de la teoría feminista en la geografía, además de revalorizar la esfera local (nueva geografía regional y estudios de las localidades). En el núcleo de las obras fundadoras del posmodernismo en geografía se encuentra la aportación de Edward Soja con Postmodern geographies: the reassertion of space in critical social theory (1989). Sin considerarse ni mucho menos a sí mismo como posmoderno, David Harvey escribió una de las obras más brillantes para comprender esta perspectiva: The condition of postmodernity (1987).

En el ámbito de la teoría de la comunicación, el nivel inicial de comprensión e interpretación introducido por la Escuela de Frankfurt encuentra su versión avanzada en las sociologías interpretativas y el interaccionismo simbólico. Miquel Rodrigo, en su obra Teorías de la Comunicación (2001) ${ }^{1}$, inscribe en la

El término "perspectiva” (funcionalista, crítica e interpretativa) se toma prestado del profesor Miquel Rodrigo Alsina, quien en su obra 
perspectiva interpretativa de la comunicación a la Escuela de Palo Alto, que cuenta con Paul Watzlawick como uno de sus miembros más destacados. Entre sus obras cabe mencionar Pragmatics of human communication: a study of interactional patterns, pathologies and paradoxes (1967) además de How real is real? Confusion, disinformation, Communication (1979). Aparte del ya mencionado interaccionismo simbólico, cabe destacar también a Erving Goffman, quien goza, según Rodrigo (2001), de autonomía propia en función de sus aportaciones, y por tanto, no debe encasillarse en una u otra corriente de pensamiento. Su obra más relevante es Frame Analysis (1974) donde se trata, abiertamente, de la organización de la experiencia de la persona individual. Finalmente, Rodrigo (2001) sitúa también al construccionismo y a la etnometodología bajo el paraguas de la perspectiva interpretativa de la comunicación.

En el año 1937 Herbert Blumer establecía la denominación Symbolic Interactionism para referirse a la psicología social y la sociología generadas en la Escuela de Chicago durante el periodo 1920-1935 (Saperas, 1998). Con posterioridad, George H. Mead consolidó los postulados señalados en primera instancia por Blumer y su obra Mind, self and society: from the standpoint of a social behaviorist (1962) resultó nuclear en el marco del interaccionismo simbólico. De este modo, el análisis estructural de la comunicación surge como refutación de los postulados de la teoría de rango intermedio. Así las cosas, la aparición de la sociología interpretativa representada, en muy buena medida, por las aportaciones de Alfred Schütz mediante obras como The phenomenology of the social world (1972), supone la explosión del estudio del individuo ${ }^{2}$ y, por tanto, de su dimensión subjetiva. La corriente de pensamiento que se inscribe en el denominado interaccionismo simbólico señala que, mediante la interacción permanente con símbolos, se construye el sentido de las situaciones sociales de la vida cotidiana. Implica, también, la ruptura con la concepción lineal de la comunicación ${ }^{3}$ y pretende describir e interpretar las acciones humanas, así como analizar el

Teorías de la comunicación. Ámbitos métodos y perspectivas (2001) realiza un valioso ejercicio de concreción de las corrientes de pensamiento que deben considerarse en teoría de la comunicación. Para Rodrigo "en la perspectiva hay, como mínimo, una aproximación semejante a un objeto de estudio parecido y una similar concepción de la comunicación dentro de la sociedad" (2001: 163).

2 De hecho, la aparición de las metodologías comprensivas, y por extensión el enraizamiento de la perspectiva interpretativa en comunicación, implica, fundamentalmente, el estudio del mundo subjetivo capitalizado por el individuo, el cual coincide con la crítica de raíz marxista que algunos de los representantes de la Escuela de Frankfurt -en concreto Marcuse y Habermas- lanzaron en relación con el uso de métodos analíticos y sus presupuestos, reforzando, de este modo, una nueva metodología de trabajo de perfil subjetivo y humanístico.

3 El modelo lineal de la comunicación es obra de Shannon y Weaver (1949), los cuales se apoyan en la descripción del proceso que sigue el acto comunicativo. La comunicación desde el modelo lineal se concibe como un proceso de transmisión de información realizado con un acto lingüístico, consciente y voluntario. En este proceso los dos elementos más importantes para el éxito de la comunicación son el emisor y el receptor, considerados individualmente. Defiende el esquema emisor -codificación (canal, mensaje, código)-descodificación-receptor. 
sentido que se deriva de esas mismas acciones. Interesa, especialmente, el estudio de los procesos de construcción de sentido por parte de las personas y del conocimiento de la sociedad (Estrada y Rodrigo, 2008). El interaccionismo simbólico debe sus preceptos iniciales a Georg Simmel y MaxWeber. El renacimiento de esta corriente, perteneciente a las denominadas sociologías interpretativas, resulta producto de la crisis en la que se ve sumido el funcionalismo de los años sesenta. El interaccionismo simbólico se desdobla en diversas modalidades sociológicas: la microsociología, iniciada por el canadiense Erving Goffman, la etnometodología, impulsada por el norteamericano Harold Garfinkel mediante su obra Studies in ethnomethodology (1967) y la sociofenomenología, como continuadora directa de Schütz y a través de Peter L. Berger, Thomas Luckman y Aaron Cicourel, quien cuenta entre sus obras con Cognitive sociology: language and meaning in social interaction (1973) (Saperas, 1998).

En el ámbito de conocimiento específico de la sociofenomenología cabe destacar la corriente constructivista, de largo recorrido en diferentes disciplinas, como la psicología, la pedagogía, la sociología o la teoría de la comunicación (Estrada y Rodrigo, 2008). Asimismo, se consolida como una de las corrientes más importantes de la perspectiva interpretativa en teoría de la comunicación. Intenta dar respuesta al proceso de construcción de significados por parte de la sociedad, así como delimitar los simbolismos que genera per se la interacción social. Por tanto, se sitúa en una perspectiva de análisis del fenómeno de la experiencia, adquiriendo, de este modo, claros tintes fenomenológicos. Asimismo, la corriente construccionista o constructivista sostiene que no se puede conocer la realidad con independencia del sujeto que la observa. Los representantes más destacados del constructivismo son Peter Berger y Thomas Luckman autores de la famosa obra The social construction of reality: a treatise in the sociology of knowledge (1967). El constructivismo parte de la base de que la realidad social es una construcción, de que el lenguaje representa y construye el mundo, las interpretaciones son subjetivas y la verdad es relativa porque está fuertemente arraigada a una historia personal y a convenciones colectivas históricas. Uno de los objetos de estudio privilegiados del construccionismo es la vida cotidiana, así como la introspección en el universo simbólico y, por extensión, en los procesos de construcción cognoscitiva.

Afín al pensamiento constructivista se sitúa Paul Watzlawick, destacado teórico de la Escuela de Palo Alto (California, Estados Unidos). Desde un marco de tipo constructivista sistémico, Watzlawick se interesó por el estudio de los procesos psicológicos de la comunicación, estableciendo, de este modo, lo que él denominó como axiomas básicos de la comunicación humana ${ }^{4}$. Entre las aportaciones teóricas de Watzlawick cabe

4 Se resumen en: no es posible "no comunicar"; los elementos de la comunicación disponen de un contenido (transmisión de datos) y un ambiente que rodea al mensaje y a los comunicantes; la naturaleza de una relación depende de cómo se ordene la secuencia de actos 
destacar la que hace referencia al proceso de "construcción comunicativa" a partir de dos elementos: el contenido -lo que se quiere comunicar- y el contexto de la comunicación -las circunstancias ambientales de la interlocución. El segundo concepto engloba al primero y adquiere el carácter de metacomunicación. El autor defiende la existencia de un tipo de comunicación "analógica” (no verbal) y la comunicación digital (que incluye los lenguajes, de carácter más abstracto). A lo largo de su aportación teórica a la comunicación, Watzlawick defendió la dualidad existente en la propia realidad. En este sentido, se refiere a una realidad de primer orden (objetividad de su estado físico y, por tanto, experimental y repetible) y a una realidad de segundo orden, más de tipo simbólico, pronunciándose en los siguientes términos: "Nunca nos enfrentamos con la realidad en sí, sino sólo con imágenes o concepciones de la realidad, es decir, con interpretaciones" (1971: 104-105). Watzlawick defiende que los seres humanos conocen la realidad a partir de procesos interpretativos de esa misma realidad. De este modo, el teórico analiza la percepción y la comunicación a modo de instancias constructivas, como construcción social de la realidad. Por tanto, la realidad es fruto de la convención interpersonal y social, de los atributos que se asignan en un momento y lugar a las diferentes partes de esa "experiencia" de la realidad, situándose muy cerca de los postulados fenomenológicos.

La perspectiva interpretativa de la teoría de la comunicación incluye también la aportación de la semiótica, que se ha perfilado como una teoría general de los signos, así como el estudio de la significación y el sentido en ciertos contextos y fenómenos de comunicación. Ahí donde hay producción e interpretación de sistemas de signos, la semiótica tiene algo que decir. La semiótica sirve a los estudios de comunicación social como una herramienta, un marco conceptual y metodológico que le permite analizar los procesos de significación de las materialidades que nos interesen (códigos lingüísticos, visuales, auditivos, virtuales...). (Karam, 2006).

En definitiva, existe un evidente paralelismo entre la evolución de la geografía y la propia de la teoría de la comunicación, como mínimo, desde los años 40 del siglo pasado. El contexto metodológico ha sido parecido e incluso se han compartido algunos conceptos, como el de espacio, aunque no así el de paisaje. Sin embargo, a pesar de haber seguido una evolución parecida, lo cierto es que no se han aprovechado las sinergias que podrían desprenderse de una interrelación más profunda entre ambas miradas, y muy especialmente en relación con el concepto de paisaje, como veremos a continuación.

comunicativos; la comunicación humana es tanto verbal como no verbal (analógica y digital); la comunicación es simétrica o complementaria. 


\section{El paisaje en la comunicación}

Iniciábamos este artículo vinculando el concepto de paisaje con el de identidad territorial. Pues bien, es precisamente esta interrelación la que explica el cada vez mayor interés ante las posibilidades de comunicación del paisaje. Sin ir más lejos, los procesos de creación de identidades territoriales vinculados a la necesaria emergencia de la imagen de marca para dotar de sentido a muchas estrategias de marketing y publicidad se sitúan, actualmente, en primera línea de interés. Veamos, a continuación, algunos de los usos comunicativos más relevantes del paisaje.

\subsection{Intangibles en el paisaje}

El tránsito hacia una visión evolucionada del paisaje desde el punto de vista de la comunicación implica, en primer lugar, buscar valores añadidos al mismo, con el fin de optimizar sus posibilidades de explotación comunicativa. Esta tendencia supone dar un paso adelante en la búsqueda del mensaje implícito en el territorio y, por tanto, resulta interesante indagar más allá de sus implicaciones físicas y/o naturales, con el fin de potenciar con fuerza los valores estéticos, morales, simbólicos e identitarios, todos ellos potencialmente comunicables, por intangibles que sean.

Cada vez más, las agencias de publicidad, las consultorías de marketing y los grupos de investigación en comunicación, entre muchos otros, centran su interés en el estudio e implementación de nuevas técnicas de comunicación territorial en el sentido más amplio de la palabra (promoción turística en sus diferentes formatos, citymarketing, branding, organización de eventos como estrategia de consumo territorial, etc.) en aras de reforzar el valor comercial y situar a las diferentes localizaciones geográficas en situación de ventaja competitiva a partir del trabajo de construcción de un mensaje emocional vinculado a un territorio concreto.

El diseño de un lenguaje de semejante naturaleza representa un esfuerzo más en la difícil tarea de definir metodologías de análisis que permitan delimitar los valores asociados a un emplazamiento concreto, más allá de una clasificación taxonómica. Se trata de delimitar las metodologías de trabajo a partir de las cuales enumerar los valores no físicos -y, por tanto, más intangibles- vinculados al espacio. En este sentido, existen algunos títulos que abren el camino hacia la lectura intangible del espacio en general y del paisaje en particular. Se trata, por ejemplo, de obras como The subtle power of intangible heritage: legal and financial instruments for safeguarding intangible heritage (2004) a cargo de Deacon, Dondolo, Mrubata y Rosalendis, además del artículo Managing world heritage cultural landscapes and sacred sites (2003) a cargo de Mechtild Rössler, entre otras muchas referencias. 
Así las cosas, el lenguaje del paisaje pretende hacer inteligibles y/o clasificables los valores intangibles que se le asocian (simbólicos, estéticos, identitarios, mitológicos) mediante el despliegue de varias técnicas que, en su conjunto, deberían aportar más luz a la ardua tarea que supone inventariar los valores intangibles de un espacio físico, así como el diseño de marcas de ciudad y turísticas con finalidades de posicionamiento identitario, turístico y territorial. Por otro lado, los procesos de mercadeo con el espacio tienen un recorrido histórico relativamente amplio -por ejemplo, en el ámbito de la promoción turística- pero, en los últimos tiempos, la necesidad de posicionar determinadas localizaciones geográficas en los niveles de creación de imagen de marca vinculados a la habilitación de identidades territoriales han disparado las estrategias que implementan estrategias de comunicación a partir de inputs territoriales que, en muy buena medida, surgen de la explotación de las enormes posibilidades comunicativas que se desprenden del paisaje.

En efecto, el paisaje desempeña un papel relevante en el proceso de formación, consolidación y mantenimiento de identidades territoriales (Nogué, 2007) y, en este sentido, deviene un argumento comunicativo central en estrategias de marketing de ciudades (citymarketing) y de promoción turística, entre otras. Es sorprendente el interés por fijar imaginarios y construir identidades territoriales, en clara disonancia con la actual homogeneización de espacios y lugares. Se demanda la "denominación de origen" de los territorios mediante la reivindicación de raíces históricas, culturales, religiosas o étnicas. Se constata, globalmente, el fortalecimiento de la variable identidad en la denominada sociedad de la información, la revalorización de los lugares y la creciente necesidad de singularizarse, de exhibir y destacar todos aquellos elementos significativos que distinguen un lugar respecto de los otros. Y el paisaje es uno de esos elementos (Nogué, 2007; 2008b).

\subsection{Paisaje, publicidad y ciudad}

En este sentido, las posibilidades que ofrece el tratamiento publicitario del paisaje resultan enormes. El lenguaje publicitario se mueve bajo las directrices de la persuasión y los usos mediáticos del paisaje pasan a desarrollar un rol avanzado en la transmisión del mensaje publicitario. Ello significa que los creativos de publicidad utilizan el ‘soporte’ paisaje no únicamente como contexto físico de un comercial publicitario, sino que aprovechan la capacidad de evocación comunicativa implícita en el propio paisaje para desarrollar los argumentos emocionales a partir de los cuales se intenta influenciar a los potenciales receptores del mensaje publicitario que se pretende transmitir. La aparición de paisajes en anuncios publicitarios es cada vez más notoria, en especial en los comerciales que promocionan la compra de automóviles y también en los anuncios de promoción turística de destinos, aunque, de forma recurrente, el paisaje adquiere protagonismo en la promoción publicitaria de cualquier tipo de bien o servicio. 
En el caso concreto de la publicidad exterior, hay algunos autores como Pacheco (2007: 121) que entienden los soportes de publicidad presentes en la urbe como "subsistemas integrantes del paisaje urbano y, por tanto, no son ajenos al proceso evolutivo que experimentan las ciudades”. En el mismo sentido se manifiesta Vizcaíno-Laorga (2007) cuando se refiere al proceso de creación de símbolos arquitectónicos o culturales vinculados a la habilitación de identidades para las ciudades. El mismo autor señala: "las entidades promotoras de turismo tienen claro que ya no se vende un producto, sino su imagen en cada país; cada visitante quiero algo distinto y hay que dárselo" (2007: 138). Por tanto, la creación de esa imagen que sitúa a las ciudades en el mercado de comercialización territorial surge, en buena medida, a partir de la que se podría denominar como ‘sugestión del paisaje’, en un intento de proyectar simbólica, cultural e identitariamente el territorio a través de la mirada del paisaje. Esa proyección audiovisual acaba cristalizando, en la mayoría de las ocasiones, en la representación mediática de un paisaje, ya sea litoral, urbano, rural o de montaña.

La representación de un paisaje es capaz de absorber y al mismo tiempo evocar toda la carga simbólica e identitaria que se pueda derivar de una campaña de comunicación destinada a promocionar un territorio. Representa, en este caso, un ejercicio de concreción audiovisual, además de optimizar el rendimiento de las posibilidades comunicativas que ofrece el paisaje en un marco de venta del espacio. El paisaje, situado en el universo de la industria publicitaria, la cual se mueve bajo los inputs de las emociones y las intangibilidades, representa una materia prima con la cual trabajar los aspectos simbólicos e identitarios presentes en el territorio.

R. Pena, en su trabajo Aprendiendo a percibir la ciudad. Metodología y estrategias didácticas (2001: 41-48), señala que el paisaje urbano no puede ser concebido únicamente como un sistema real que requiere un "conocimiento objetivo" pues, en tanto que entorno percibido, es también un conjunto de signos que se leen e interpretan según el significado que le otorga cada individuo. Por tanto, se sitúa también en la dimensión doctrinal de la geografía de la percepción que, tal y como señala Maderuelo (2005), ha puesto de manifiesto cómo la imagen subjetiva del medio tiene una gran importancia en el comportamiento espacial de las gentes y cómo, además, esta imagen puede diferir de modo notable entre unas y otras personas, según la procedencia, el nivel cultural y la experiencia viajera, y cambiar, también, a lo largo del tiempo. El paisaje, por tanto, se está convirtiendo, cada vez más, en un producto de consumo per se, exaltando la experiencia con el territorio, así como la búsqueda de nuevas sensaciones.

El uso mediático del paisaje se inserta de lleno en una estrategia global de marketing de ciudades a través del uso comunicativo de elementos intangibles y emocionales. 
Norberto Muñiz (2007: 151) se pronuncia en los siguientes términos: "La caracterización urbana debe hacerse en función de sus respectivas identidades. La identidad de las ciudades se articula en relación con atributos -singulares o múltiples- que les confieren notoriedad en los intercambios socio-económicos”. El aspecto capital en el proceso de construcción simbólica de un territorio -ya sea país, ciudad, villa o aldeaes la intervención prácticamente segura de una infraestructura, monumento y/o edificio emblemático integrado en un paisaje que actúa a modo de icono urbano que desarrolla las funciones de imaginario visual y comercializable en el proceso de "compra" de una ciudad entendida como bien de consumo.

Los retos futuros de las ciudades occidentales girarán en torno a su posicionamiento en el mercado a partir de la exaltación de valores intangibles (calidad de vida, sostenibilidad, interculturalidad, tolerancia, talento, innovación), vehiculados, en la mayor parte de los casos, a través de la creación de una imagen de marca que emana de la puesta en valor, en este caso, del paisaje urbano. Carmen Gaona (2007: 172), en relación con la construcción simbólica de la ciudad, afirma lo siguiente: "Hacer ciudad es habitar en ella, pasear e intercambiar símbolos por sus calles; las asociaciones, los movimientos sociales y culturales que de ella se desprenden contribuyen a construir la ciudad; los lazos afectivos y sociales que establecemos entre las ciudadanas y los ciudadanos contribuyen, también, entre otros múltiples elementos y procesos, a construir la ciudad entre todos. En definitiva, concibo lo urbano como formas de convivencia comunicativa, de construcción cultural y de referente identitario individual y colectivo”. Así las cosas, la producción social del significado de "lo urbano" surge de la interacción de los actores urbanos entre sí con el espacio que les rodea (Gaona, 2007: 174).

En definitiva, el paisaje se está conviertiendo en una pieza clave en la promoción publicitaria de territorios y ciudades, y no sólo en el marco de estrategias de promoción turística, sino también -y sobre todo- en los procesos de creación de identidades territoriales, en los que se llega incluso a incurrir, a menudo, en una especie de reiteración, de redundancia comunicativa entre la realidad y su representación o, si se prefiere, entre el original y la copia. Un curioso ejemplo en este sentido es el reciente fenómeno de proliferación de enormes carteles publicitarios en las principales vías de entrada de muchos pueblos y ciudades en los que se anuncia ni más ni menos que la propia localidad a través de una imagen de la misma (Nogué, 2008a). Se trata de una fotografía de dimensiones colosales en la que se muestra la imagen más típica y estereotipada de la ciudad o el pueblo en cuestión. Lo curioso del caso es que estos paneles informativos suelen estar emplazados de tal manera que se percibe, a la vez, el paisaje real y el representado, el original y la copia, hasta el punto de que uno no sabe muy bien qué mirar primero ni cómo mirarlo, puesto que las dos imágenes -la real y su correspondiente representación- son la misma, al menos aparentemente. 
En cierta medida nos hallamos ante una versión banal y superficial de algo mucho más profundo que en la historia del arte ha sido fundamental: el estudio de las complejas relaciones entre la realidad y su representación. El arte se ha planteado y reformulado constantemente estas relaciones, hasta el punto de que, en el fondo, la historia del arte es, en buena medida, la historia de este binomio, de vez en cuando expresado de manera explícita, ingeniosa y sagaz, como en Las Meninas, de Velázquez, o en Dalí de espaldas pintando a Gala de espaldas, de Salvador Dalí. En los movimientos realistas estas relaciones se han encarado siempre desde una perspectiva global, mientras que en las vanguardias artísticas se han planteado de manera algo más fragmentada, más focalizada, ya sea en el color (los impresionistas), en la forma (los cubistas) o en el movimiento (los futuristas), por poner sólo unos ejemplos. El arte contemporáneo ha recuperado de nuevo la perspectiva global y holística de dichas relaciones, perdida en parte en el último siglo y medio. Esta recuperación se observa de manera diáfana en el arte conceptual, ya desde aquella obra clásica de Peter Campus, Interface (1972), en la que se unifica en una única visión el reflejo del espectador sobre la obra y la proyección sobre la misma de un vídeo del propio espectador grabado en directo.

Los carteles a los que aquí aludimos suponen una versión light y muy descafeinada de una idea que el arte conceptual retomó hace ya cuarenta años, pero sin su intencionalidad experimental y creativa ni su reflexión crítica sobre los siempre difusos límites entre realidad y ficción. Nos hallamos ahora de lleno en una sociedad de la visualización inducida, en la que la construcción de imágenes y, por descontado, de paisajes, ha triunfado. Las imágenes del paisaje son tan extraordinariamente cotidianas en nuestro universo visual que han llegado a orientar nuestra percepción de la realidad. Así, en el proceso de apreciación estética del paisaje, lo que se sabe (la información visual sobre el paisaje) condiciona y cuestiona lo que se experimenta (la propia vivencia del paisaje). A menudo calificamos de bello un paisaje cuando podemos reconocer en él un antecedente avalado mediáticamente y, de hecho, el éxito o el fracaso de la experiencia turística y, más concretamente, viajera dependerá, en buena medida, del nivel de adecuación de los paisajes contemplados "en directo" a aquellas imágenes de los mismos que, previamente, se nos indujo a visitar y a conocer desde una revista, un documental de televisión o una agencia de viajes.

He ahí la definitiva mercantilización de los lugares y de sus paisajes, tan propia de las sociedades y de las economías posmodernas y posindustriales. Una de las paradojas fundamentales de la posmodernidad -en el marco de la crisis de la autenticidad- es la clara diferenciación entre la realidad y su representación y la correspondiente celebración de la inautenticidad, algo muy en línea con la filosofía que inspira los parques temáticos. Parece claro que vamos camino de la tematización del conjunto del paisaje y es desde esta perspectiva desde la que quizá se interpreten mejor los mencionados carteles. Se nos enseña lo que ya 
podríamos ver por nosotros mismos no por puro citymarketing barato, sino porque, de acuerdo con lo dicho más arriba, el paisaje real, para adquirir más relevancia, deber ser mediatizado; debe pasar por el poderoso filtro de la imagen, a ser posible estereotipada (y, aún mejor, arquetípica). El consumo de los lugares no es completo si antes no hemos consumido visualmente sus imágenes, como ya desarrolló en su día John Urry al explorar a fondo la "mirada turística" en el marco de una sugerente semiótica de la imagen visual. Sucede con el paisaje algo parecido a lo que Kenneth Gergen planteaba en El yo saturado (1992):

"La cuestión no es saber si las relaciones entabladas a través de los medios se aproximan en su significación a las normales, sino más bien si las relaciones normales pueden aproximarse a los poderes del artificio. [...] Las vacaciones dejan de ser reales si no las hemos filmado; las bodas se convierten en acontecimientos preparados para la cámara fotográfica y el vídeo; los aficionados al deporte prefieren ver los encuentros por la televisión en lugar de acudir al estadio, ya que lo que ven en la pantalla les parece más próximo a la realidad. Recurrimos cada vez más a los medios, y no a nuestra percepción sensorial, para que nos digan lo que pasa” (Gergen: 85).

\section{A modo de conclusión}

Es cada vez más relevante el papel que desarrolla el territorio como mediador de procesos de comunicación, así como en los procesos de consolidación o creación de identidades locales, a todas las escalas. Ahí es, precisamente, donde el paisaje adquiere un importante protagonismo, porque este es, per se, un aparador cultural y un escenario de lenguajes. Si es verdad que en el espacio se encuentra el mensaje y, por tanto, el territorio con carga simbólica ejerce la función de transmisor de este mismo mensaje, también lo es que el paisaje adquiere en este proceso un protagonismo indiscutible. La puesta en marcha de una parcela de estudio multidisciplinar que apueste por la inteligibilidad e interpretación del mensaje implícito en el paisaje, resultado de procesos de retroalimentación con la ciudadanía, tiene claras implicaciones a nivel comunicativo. En este sentido, se hace indispensable el inicio de una línea de investigación que sea capaz de ofrecer una salida fiable a la emergente demanda de estudios que relacionan la comunicación y el paisaje, en unos momentos en los que el paisaje se ha convertido en una pieza clave de las nuevas políticas de ordenación del territorio, así como también en infinidad de debates suscitados en ámbitos sociales y culturales que apuestan por la aplicación de la filosofía que emana del Convenio Europeo del Paisaje.

La necesidad de descodificar los significados que se atribuyen al paisaje, la interactuación sociedad-paisaje (comunicación intra e interpersonal) y, más recientemente, los usos de paisaje a modo de 'aparador territorial mediático’ en el ámbito, por ejemplo, de la comunicación publicitaria o del citymarketing, deberían servir para plantearse el estudio de lo que, de alguna manera, representa la sugestión del paisaje, de claros 
tintes emocionales y simbólicos y, por tanto, también comunicacionales. En efecto, los presupuestos teóricos proporcionados por la denominada perspectiva interpretativa de la comunicación, capitalizada por las aportaciones de la sociología interpretativa de Alfred Schütz, la intersubjetividad, la fenomenología y los métodos de construcción y comprensión de la realidad asociados a la generación de simbolismos e imaginarios individuales y colectivos resultado de procesos de interacción simbólica, resultan ser, a nuestro entender, el marco de estudio apropiado para el afronte del análisis de las implicaciones comunicativas del paisaje. Por tanto, los métodos y el marco teórico sugieren, también, un planteamiento epistemológico de tipo cualitativo. A su vez, las denominadas "geografías del sujeto" (geografía de la percepción, humanística y posmodernismo en geografía) presentan numerosos puntos de encuentro con los presupuestos teóricos de la perspectiva interpretativa de la comunicación. En este sentido, las tendencias de pensamiento coincidente en comunicación y en geografía, sobre todo en lo que se refiere a la interpretación de vivencias y simbolismos, proporcionan al vínculo “paisaje y comunicación” amplias perspectivas de estudio.

\section{Referencias bibliográficas}

Albet, A. (1994): "Geografia, postmodernisme, geografia postmoderna: aportacions al debat”, Documents d'Anàlisi Geogràfica, n. 24, pp. 7-11.

Anderson, R. y Ross, V. (2000): Questions of Communications: A practical introduction to theory. New York: St. Martin's Press. Appleton, J. (1986): The experience of landscape. United Kingdom: Hull University Press.

Bailly, A. (1977): La Perception de l'espace urbain: les concepts, les néthodes d'étude, leurs utilsation dans la recherche géographique. París: C. R. U.

Berger, P. y Luckmann, T. (1967): The social construction of reality: a treatise in the sociology of knowledge. New York: Anchor Books, Doubleday.

Blumer, H. (1969): Symbolic Interaccionism. Perspective and method. Englewood Cliffs, NJ: Prentice-Hall.

Buttimer, A. (1983): The practice of geography. London: Longman.

Cicourel, A. (1973): Cognitive sociology: language and meaning in social interaction. Harmondsworth: Penguin Education. Consejo Europeo (2000): Convenio Europeo del Paisaje. Florencia.

Deacon, Harriet et al. (2004): The subtle power of intangible heritage: legal and financial instruments for safeguarding intangible heritage. Cape Town: Human Science Research Council. URL: [http://www.hsrcpress.ac.za/product.php? productid=2044\&freedownload=1]. Fecha de consulta: 23 de octubre de 2008. 
Downs, R.M. (1970): “Geographic space perception: part approaches and future prospects”, Progress in Geography, vol. 2, pp. 66-108.

Dudley, N., Higgins-Zogib, L y Mansourian, S. (eds.) (2005): Beyond belief: linking faiths and protected areas to support biodiversity conservation. United Kingdom: WWF.

Estrada, A. y Rodrigo, M. (2008): L'estudi de la teoria de la comunicació i la informació. Barcelona: Fundació de la Universitat Oberta de Catalunya.

Fernández Christilieb, P. (2000): “El territorio instantáneo de la comunidad posmoderna”, en Lindón, A. (dir.): La vida cotidiana y su espacio temporalidad. Barcelona: Anthropos, pp. 147-170.

Fremont, A. (1976): La región, espace vécu. París: P. U. F.

Gaona, C. (2007): “Nuevos símbolos urbanos desde la publicidad”, en Baladrón, A. et al.: Publicidad y Ciudad. Sevilla-Zamora: Ediciones y publicaciones Comunicación Social, pp. 172-188.

Garfinkel, H. (1967): Studies in ethnometodology. Englewood Cliffs, N.J.: Prentice-Hall.

Gergen, K. (1992): El yo saturado: dilemas de identidad en el mundo contemporáneo. Barcelona: Paidós.

Gobierno de Navarra (2002): El patrimonio intangible y otros aspectos relativos a los itinerarios culturales [Congreso Internacional del Comité Internacional de Itinerarios Culturales (CIIC) de ICOMOS]. Departamento de Educación y Cultura.

Goffman, E. (1974): Frame analysis. An essay on the organization of experience. New York: Harper and Row.

González, F. (1981): Ecología y paisaje. Madrid: Hermann Blume.

Gould, P. (1974): Mental maps. Harmondsworth: Penguin Books.

Harvey, D. (1989): The condition of postmodernity. London: Blackwell.

Ittelson, W.H. (1973): Environtment and cognition. New York: Seminar Press.

Karam, T. (2006): Introducción a la semiótica. Bellaterra: Institut de la Comunicació. Universitat Autònoma de Barcelona.

Krupnik, I., Mason, R.; Horton, T.W. (eds.) (2004): Northern ethnographic landscapes: perspectives from circumpolar nations. Washington: Artic Studies Center, National Museum of Natural History, Smithsonian Institution.

Linch, K. (1960): The image of the city. Cambridge: M. I. T. Press.

Lindón, A. (dir.) (2000): La vida cotidiana y su espacio-temporalidad. Barcelona: Anthropos.

Lowenthal, D. (1961): “Geography, Experience and Imagination: Towards a Geographical Epistemology", Annals of the Association of American Geographers vol. 51, n. 3 (sep., 1961), pp. 241-260.

Maderuelo, J. (2005): El paisaje: génesis de un concepto. Madrid: Abada editores. 
Mallarach, J.M.y Papayannis, T. (eds.) (2007): Protected areas and spirituality: proceedings of the First Workshop of The Delos Initiative, Montserrat, 2006. Gland: IUCN; Montserrat: Publicacions de l'Abadia de Montserrat.

Martínez de Pisón, E. (1983): “Cultura y ciencia del paisaje”, Agricultura y Sociedad, no 27, pp. 9-32.

Martínez de Pisón, E. y Álvaro, S. (2002): El sentimiento de la montaña: doscientos años de soledad. Madrid: Desnivel.

Mead, G.H. (1962): Mind, self and society: from the standpoint of a social behaviorist. Chicago: University of Chicago Press.

Mehrabian, A. (1976): Public places and private spaces: the phycology of work, play and living environtments. New York: Basic Books Inc.

Mela, A. (1994): La città come sistema de comunicazioni sociali. Milano: Franco Angeli.

Moles A. (1972): "Socio-économie des mass-media: vers une écologie de la comunication" en Économie et Sociétés, Cahiers de l'Institut de Science Economique Appliquée, vol. IV, pp. 731-773.

Moragas, M. (1981): Teorías de la comunicación. Investigaciones sobre medios en América y Europa. Barcelona: Gustavo Gili.

Muñiz, N. (2007): "Marketing de ciudades: de la gestión estratégica y de infraestructuras a la creatividad y los valores", en Baladrón, A. et al.: Publicidad y Ciudad. Sevilla-Zamora. Ediciones y publicaciones Comunicación Social, pp. 149-171.

Nogué, J. y Romero, J. (eds.) (2006): Las otras geografías. Valencia: Tirant Lo Blanch.

Nogué, J. (ed.) (2007): La construcción social del paisaje. Madrid: Biblioteca Nueva.

- (2008a): Entre paisajes. Barcelona: Àmbit.

- (2008b): El paisaje en la cultura contemporánea. Madrid: Biblioteca Nueva.

Ortega Valcárcel, J. (2000): Los horizontes de la geografía. Barcelona: Ariel.

Pacheco, M. (2007): “La ciudad como escenario de la comunicación publicitaria”, en Baladrón, A. et al: Publicidad y Ciudad. Sevilla-Zamora: Ediciones y publicaciones Comunicación Social, pp. 111-128.

Pena, R. (2001): “Aprendiendo a percibir la ciudad. Metodología y estrategias didácticas”, Íber: Didáctica de las Ciencias Sociales, Geografía e Historia, vol. 8, n. 27, pp. 41-48.

Pol, E. (2002): “El modelo dual de la apropiación del espacio”, en García Mira, R., Sabucedo, J.M. y Romay, J. (eds.): Psicología y Medio Ambiente. Aspectos psicosociales, educativos y metodológicos. A Coruña: Asociación galega de estudios e investigación psicosocial, pp. 123-132.

Quivy, R. y Van Campenhoudt, L. (1997): Manual de recerca en ciències socials. Barcelona: Editorial Herder.

Reguillo, R. (1997): “Ciudad y Comunicación. Densidades, Ejes y Niveles”, Diálogos de la Comunicación. Revista de la Federación Latinoamericana de Facultades de Comunicación Social, n. 47, pp. 1-10. 
Rodrigo, M. (2001): Teorías de la comunicación. Ámbitos, métodos y perspectivas. Bellaterra: Servei de Publicacions de la Universitat Autònoma de Barcelona.

Rössler, M. (2003): “Managing world heritage cultural landscapes and sacred sites”, World Heritage Papers, n. 13, pp. 45-48.

San Eugenio, J. (2007): “La delimitación de los elementos intangibles del paisaje: indicios de comunicación”, Actas del XX Congreso de Geógrafos Españoles: Sevilla.

San Eugenio, J. (2008): “Comunicación y territorio”, en Portal de la Comunicación. Instituto de la Comunicación (InCom). Bellaterra: Universitat Autònoma de Barcelona. Disponible en: [http://www.portalcomunicacion.com/esp/ n_aab_lec_1.asp?id_llico=36].

Santarelli, S. y Campos, M. (2002): Corrientes epistemológicas, metodología y prácticas en geografía. Buenos Aires: Editorial de la Universidad Nacional del Sur.

Saperas, E. (1998): Manual básico de teoría de la comunicación. Barcelona: CIMS.

Schütz, A. (1972): The Phenomenology of the social World. Heinemann: Educational Books.

Soja, E. (1989): Postmodern geographies: the reassertion of space in critical social theory. London: Verso.

Sorre, M. (1957): Rencontres de la géographie et de la sociologie. París: Marcel Rivieére.

Sperber, D. y Wilson, D. (1994): La relevancia. Madrid: Visor.

Tuan, YF. (1974): Topophilia: a study of environmental perception, attitudes and values. Englewood Cliffs, New Jersey: Prentice Hall.

Unesco (2003): Convención para la salvaguarda del patrimonio cultural inmaterial. París. URL: [http://unesdoc. unesco.org/images/0013/001325/132540s.pdf]. Fecha de consulta: 27 de julio de 2008.

Urry, J. (1990): The tourist gaze: leiseure and travel in contemporany societies. London: Sage.

Valera, S. (1997): "Estudio de la relación entre el espacio simbólico urbano y los procesos de identidad social”, Revista de Psicología Social, vol. 12, pp. 17-30.

Vizcaíno-Laorga, R. (2007): “La ciudad percibida: tradición y tecnología” en Baladrón, A. et al.: Publicidad y Ciudad. Sevilla-Zamora: Ediciones y publicaciones Comunicación Social, pp. 129-146.

Watzlawick, P. et al. (1967): Pragmatics of human communication: a study of interactional patterns, pathologies and paradoxes. New York: W.W. Norton.

- (1971): How real is real? Confusion, desinformation, Communication. New York: Spring Books.

Winkin, Y. (1994): La nueva comunicación. Barcelona: Kair. 